\title{
Tribological Properties of Aluminum Alloy treated by Fine Particle Peening/DLC Hybrid Surface Modification
}

\author{
Y. Amano ${ }^{1}$, H. Nanbu ${ }^{1}$, Y. Kameyama ${ }^{2}$ and J. Komotori ${ }^{3, a}$ \\ ${ }^{1}$ Graduate School of Science and Technology, Keio University, 3-14-1 Hiyoshi, Kouhoku-ku, \\ Yokohama-shi, Kanagawa, 223-8522, Japan \\ ${ }^{2}$ RIKEN, 2-1, Hirosawa, Wako-shi, Saitama, 351-0198, Japan \\ ${ }^{3}$ Department of Mechanical Engineering, Keio University, 3-14-1, Hiyoshi, Kouhoku-ku, \\ Yokohama-shi, Kanagawa, 223-8522, Japan
}

\begin{abstract}
In order to improve the adhesiveness of the DLC coating, Fine Particle Peening (FPP) treatment was employed as pre-treatment of the DLC coating process. FPP treatment was performed using $\mathrm{SiC}$ shot particles, and then AA6061-T6 aluminum alloy was DLC-coated. A SiC-rich layer was formed around the surface of the aluminum alloy by the FPP treatment because small chips of shot particles were embedded into the substrate surface. Reciprocating sliding tests were conducted to measure the friction coefficients. While the DLC coated specimen without FPP treatment showed a sudden increase in friction coefficient at the early stage of the wear cycles, the FPP/DLC hybrid treated specimen maintained a low friction coefficient value during the test period. Further investigation revealed that the tribological properties of the substrate after the DLC coating were improved with an increase in the amount of Si at the surface.
\end{abstract}

Keywords: Fine Particle Peening, Aluminum alloy, Diamond-Like Carbon, Surface modification, Tribological properties

\section{Introduction}

Aluminum alloys have been widely used in industrial applications because of their high strength-toweight ratio and good recyclability; however, their friction and wear behavior are unsatisfactory. In order to improve their tribological properties, it is necessary to perform surface treatment on them.

One of the methods of improving the tribological properties of aluminum alloys is DiamondLike Carbon (DLC) coating. DLC films exhibit excellent tribological properties [1-4]; however, the practical applications of DLC coating have some limitations due to their low adhesion to aluminum alloy in general [5]. In order to improve the adhesiveness of the DLC coating, the use of metallic and/or non metallic interlayers has been explored. Previous studies have indicated that a Ti, W or $\mathrm{SiC}$ interlayer improved DLC/substrate interfacial adhesion, resulting in good tribological properties [6-9]. However, these methods are time consuming, thus increasing production cost.

\footnotetext{
a e-mail : komotori@mech.keio.ac.jp
} 
In this study, we introduced Fine Particle Peening (FPP) treatment as pre-treatment of the DLC coating process. The authors $[10,11]$ reported that small chips of shot particles were embedded into the substrate surface during the FPP treatment. The surface layer created by the treatment was expected to enhance the DLC/substrate interfacial adhesion, resulting in good tribological performance.

The aim of this study is to examine the possibility of improving the adhesiveness of the DLC coating on aluminum alloy by FPP treatment.

\section{Experimental procedures}

The material used in this study was AA6061-T6 aluminum alloy with a chemical composition shown in Table 1. Disks of AA6061-T6 aluminum alloy, $15 \mathrm{~mm}$ in diameter and $4 \mathrm{~mm}$ in thickness, were machined from rods and then polished with \#320, \#500, \#1000 and \#1200 emery paper.

Figure 1 shows a flowchart illustrating the surface treatments applied to the specimens. Four types of surface treatments were performed. The Polished series was mirror-finished using a colloidal silica suspension. The Polished-D series was mirror-finished and then DLC-coated. The FPP series was prepared by FPP treatment using SiC shot particles $50 \mu \mathrm{m}$ in diameter. The FPP-D series was prepared by combining FPP treatment and DLC coating.

The parameters of the FPP treatment are shown in Table 2, and typical features of SiC shot particles can be seen in Figure 2. The DLC films were deposited by an ionized-vapor deposition method on the specimens to a thickness of $1 \mu \mathrm{m}$. The reactant used was $\mathrm{C}_{6} \mathrm{H}_{6}$ gas with a pressure of $4.0 \times 10^{-3} \mathrm{~Pa}$. Coating deposition was carried out for 2 hours. Bias voltage and temperature of substrate were $-2 \mathrm{kV}$ and $250^{\circ} \mathrm{C}$, respectively.

Surface microstructures of the specimens were examined using scanning electron microscopy (SEM) and energy dispersive X-ray spectroscopy (EDS). The surface roughness was measured using a confocal laser microscope.

To determine the friction coefficients of the DLC-coated and uncoated specimens, reciprocating pin-on-disk friction tests were carried out. The parameters used during the friction tests are shown in Table 3. The friction coefficients were measured while the reciprocating ball moved in the forward direction. The adhesiveness of the DLC coating was estimated according to the variations of the friction coefficients. The wear track on each specimen was also examined using SEM and EDS.

Table 1. Chemical composition of AA6061-T6 aluminum alloy (wt \%).

\begin{tabular}{cccccccc}
\hline $\mathrm{Si}$ & $\mathrm{Fe}$ & $\mathrm{Cu}$ & $\mathrm{Mn}$ & $\mathrm{Mg}$ & $\mathrm{Zn}$ & $\mathrm{Cr}$ & $\mathrm{Al}$ \\
\hline $0.4 \sim 0.8$ & $<0.7$ & $0.15 \sim 0.40$ & $<0.15$ & $0.8 \sim 1.2$ & $<0.25$ & $0.01 \sim 0.35$ & Bal. \\
\hline
\end{tabular}

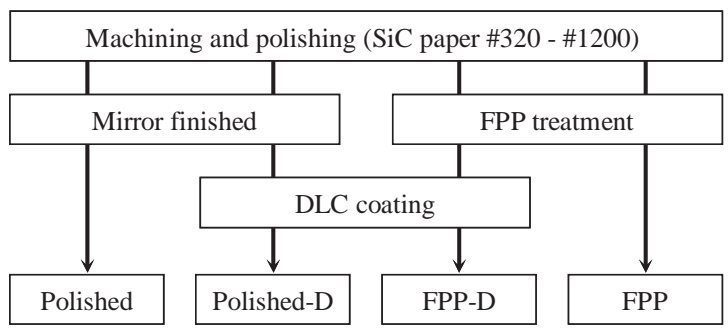

Fig. 1. Flowchart illustrating specimen preparation.

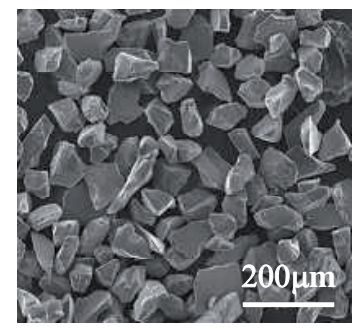

Fig. 2. Typical features of SiC shot particles. 
14th International Conference on Experimental Mechanics

Table 2. FPP treatment conditions.

\begin{tabular}{ll}
\hline Shot particle & $\mathrm{SiC} \# 240$ \\
\hline Particle diameter & $50 \mu \mathrm{m}$ \\
\hline Particle supply rate & $3 \mathrm{~g} / \mathrm{s}$ \\
\hline Peening time & $10 \mathrm{~s}$ \\
\hline Peening pressure & $0.6 \mathrm{MPa}$ \\
\hline Nozzle distance & $100 \mathrm{~mm}$ \\
\hline
\end{tabular}

Table 3. Tribological testing conditions.

\begin{tabular}{ll}
\hline Counter material & $\begin{array}{l}\phi 3.175 \mathrm{~mm} \\
\text { alumina ball }\end{array}$ \\
\hline Load & $1.47 \mathrm{~N}$ \\
\hline Length of wear track & $8 \mathrm{~mm}$ \\
\hline Linear speed & $30 \mathrm{~mm} / \mathrm{s}$ \\
\hline
\end{tabular}

\section{Results}

Figure 3 shows SEM image and EDS image of Si of the FPP series at longitudinal section. SiC particles, less than $3 \mu \mathrm{m}$ in diameter, are clearly observed around the surface, embedded into the substrate surface during the FPP process.

Figure 4 shows SEM images of the DLC coated specimens at longitudinal section. Figure 5 shows the mean surface roughness values for each series. These results show that a surface topography created by the FPP treatment resulted in an increase in the surface roughness. The surface roughness of the FPP and FPP-D series are almost the same. This implies that the DLC film was deposited along the original surface.

Figure 6 shows the friction coefficients of each specimen as a function of sliding cycles [12]. The Polished-D and FPP-D series with DLC coating show lower friction coefficients during the earlier stages of sliding compared to those of the Polished and FPP series without DLC coating. The FPP-D series maintained a low friction coefficient value during the test period, while the friction coefficient of the Polished-D series rapidly increased at a 2000 sliding cycles, gradually decreasing and becoming the same as that of the Polished series. These results imply that the adhesiveness of the DLC coating was improved by the FPP treatment.
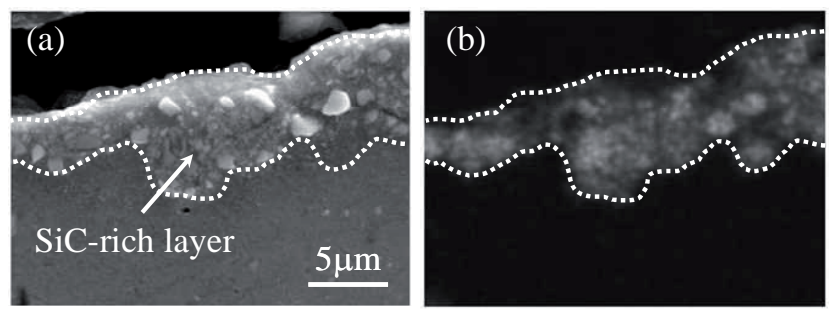

Fig. 3. SEM image and EDS image of Si of the FPP series at longitudinal section. (a) SEM image, (b) Si image corresponding to (a), White areas in (b) indicate Si. (FPP condition: $0.6 \mathrm{MPa}, 3 \mathrm{~g} / \mathrm{s}, 10 \mathrm{~s}$ )
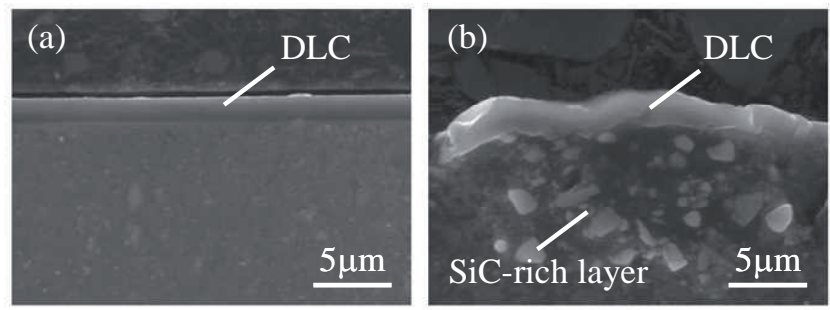

Fig. 4. SEM images of the Polished-D series and FPP-D series at longitudinal section.

(a) Polished-D series, (b) FPP-D series. 


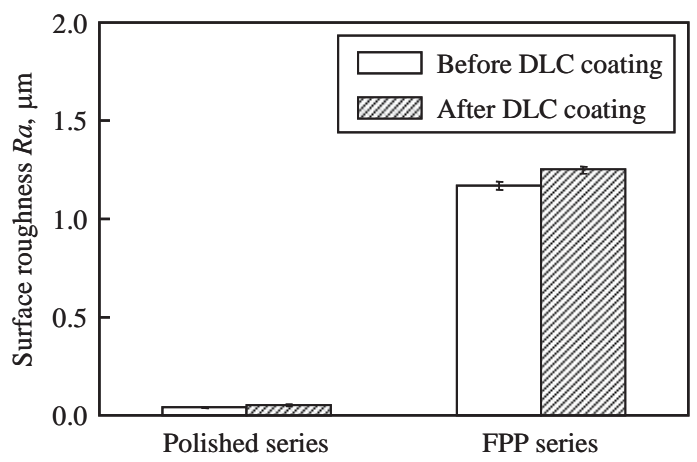

Fig. 5. Surface roughness of the specimens. (mean \pm S.D., $n=10$ )

Figure 7 shows the wear track of the Polished-D and FPP-D series after 4000 cycles. In the case of the Polished-D series, the DLC film was completely destroyed in the wear track. It is considered that the sudden increase in friction coefficient observed in Figure 6 was caused by this delamination. On the other hand, the worn surface of the FPP-D series represents considerably different features compared to those of the Polished-D series. The width of the wear scar was much narrower than that of the Polished-D series. The DLC film of the FPP-D series largely remained although the original surface appeared locally. This may be the reason that the FPP-D series maintained a low friction coefficient value for the duration of the test period (as shown in Figure 6).

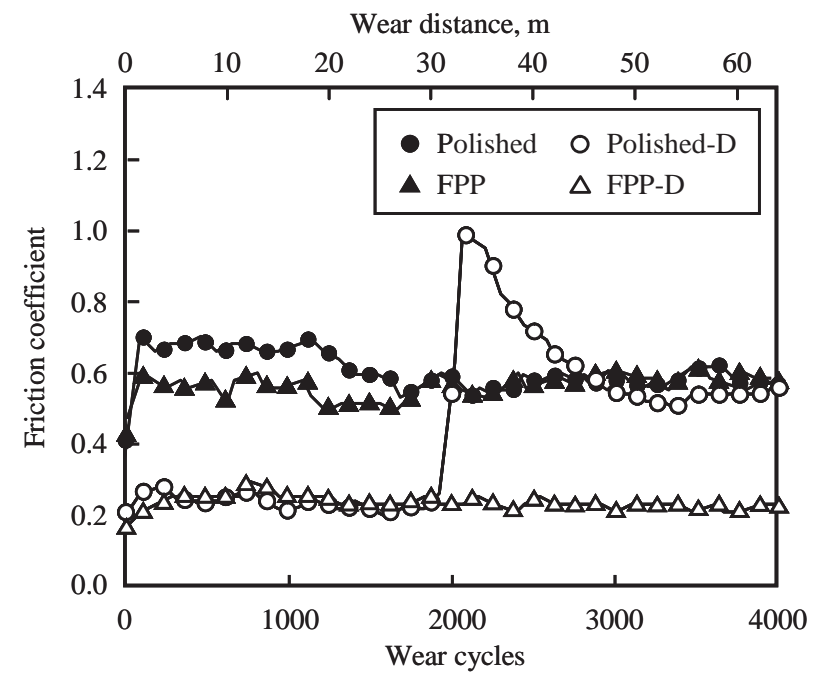

Fig. 6. Friction coefficients as a function of wear cycles [12].
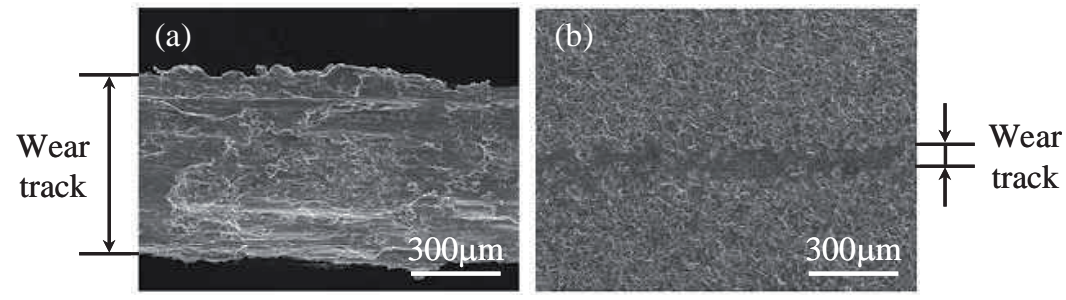

Fig. 7. SEM images of the wear track of the Polished-D and FPP-D series after 4000 cycles.

(a) Polished-D series, (b) FPP-D series. 


\section{Discussion}

In general, the wear rate of DLC coating increases with increased surface roughness [13, 14]. The FPP treatment roughened the substrate surface (as shown in Figure 5); however, the authors [15, 16] reported that the amount of transferred elements of shot particles was influenced by the FPP parameters which were peening pressure, particle supply rate and particle size. In order to investigate the effect of the amount of $\mathrm{SiC}$ at the surface on the adhesiveness of the DLC coating, we prepared three types of specimens with a different amount of Si (14at.\%, 17at.\% and 22at.\%) at the surface, and almost all the same surface roughness. The detailed FPP parameters for each series are listed in Table 4. After the DLC coating, reciprocating sliding tests were conducted to measure the friction coefficients of wear cycles.

Figure 8 shows the variations of the friction coefficients as a function of wear cycles. The DLC coated specimen without FPP treatment ( $\mathrm{Si} 0$ series) showed a sudden increase in friction coefficient at the early stage of the wear cycles. In the case of FPP/DLC hybrid treated specimen with 22at.\% of Si content, however, no change of friction coefficient was observed even at 10,000 cycles of wear. Figure 8 also showed that the more $\mathrm{Si}$, the better the adhesiveness. These results show that the $\mathrm{SiC}$ rich layer created by the FPP treatment plays an important role in suppressing the delamination of the DLC coatings, keeping the friction coefficient low and limiting wear.

Table 4. FPP treatment conditions.

\begin{tabular}{|c|c|c|c|c|c|}
\hline Series name & Shot particle & Pressure (MPa) & Particle supply rate $(\mathrm{g} / \mathrm{s})$ & $R a(\mu \mathrm{m})$ & $\mathrm{Si}$ (at.\%) \\
\hline Si 0 & - & - & - & 0.031 & 0.21 \\
\hline Si 14 & $\mathrm{SiC} \# 240$ & 0.1 & 3.0 & 0.771 & 13.58 \\
\hline Si 17 & \multirow{2}{*}{$\mathrm{SiC} \# 400$} & 0.4 & 0.5 & 0.777 & 16.83 \\
\hline Si 22 & & 0.6 & 1.0 & 0.749 & 21.91 \\
\hline
\end{tabular}

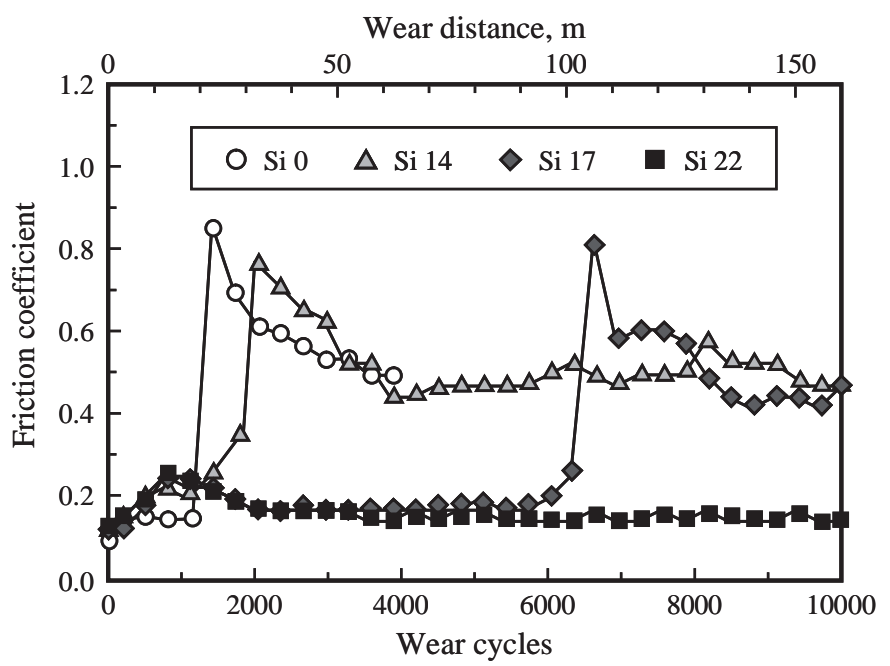

Fig. 8. Friction coefficients as a function of wear cycles. 


\section{Conclusions}

In the present study, we examined the possibility of improving the adhesiveness of the DLC coating on aluminum alloy by FPP treatment using $\mathrm{SiC}$ shot particles. Tribological properties were investigated to clarify how the FPP treatment improved DLC adhesion. Results are summarized as follows.

(1) FPP treatment roughened the substrate surface and formed a SiC-rich layer on the surface. This was because small chips of shot particles were embedded into the substrate surface during the FPP process.

(2) The DLC films deposited on the aluminum alloy substrate pre-treated by the FPP treatment using $\mathrm{SiC}$ shot particles maintained a low friction coefficient value during the test period. The tribological properties of DLC coated specimens with FPP treatment were improved with an increase in the amount of $\mathrm{Si}$ at the surface. These results suggest the practical applications of the FPP/DLC hybrid surface modification process.

\section{References}

1. C. Donnet, Surface and Coatings Technology, 100-101, 180 (1998)

2. A. Grill, Diamond and Related Materials, 8, 428 (1999)

3. D. Sheeja, B.K. Tay and L.N. Nung, Diamond and Related Materials, 13, 184 (2004)

4. Z.F. Zhou, K.Y. Li, I. Bello, C.S. Lee and S.T. Lee, Wear, 258, 1589 (2005)

5. R. Cruz, J. Rao, T. Rose, K. Lawson and J.R. Nicholls, Diamond and Related Materials, 15, 2055 (2006)

6. M. Xu, X. Cai, Y. Liu, S. Pu and P.K. Chu, Diamond and Related Materials, 17, 1844 (2008)

7. H. Nakamori, H. Tokisue, K. Kaga and M. Hiratsuka, Journal of Japan Institute of Light Metals, 56, 77 (2006)

8. X. Lifang, Y. Zhaohui and L. Jiaxuan, Wear, 257, 599 (2004)

9. H. Nomura, H. Akebono and H. Suzuki, Transactions of the Japan Society of Mechanical Engineers, SeriesA, 72, 907 (2006)

10. H. Nanbu, S. Kikuchi, Y. Kameyama and J. Komotori, Journal of Solid Mechanics and Materials Engineering, 3, 328 (2009)

11. Y. Kameyama and J. Komotori, Journal of Materials Processing Technology, 209, 6146 (2009)

12. H. Nanbu, S. Kikuchi, Y. Kameyama and J. Komotori, World Tribology Congress, 472 (2009)

13. J. Jiang and R.D. Arnell, Wear, 239, 1 (2000)

14. K. Miyoshi, R.L.C. Wu, A. Garscadden, P.N. Barnes and H.E. Jackson, Journal of Applied Physics, 74, 4446 (1993)

15. Y. Kameyama, J. Komotori and E. Shimodaira, The society of Materials Science, Japan, 53, 226 (2004)

16. Y. Kameyama and J. Komotori, Journal of Solid Mechanics and Materials Engineering, 2, 1338 (2008) 